\title{
Formation and Efficient Estimation of Stochastic Frontier Production Function
}

\section{OPEN ACCESS}

Manuscript ID:

ECO-2021-09044084

Volume: 9

Issue: 4

Month: September

Year: 2021

P-ISSN: 2319-961X

E-ISSN: 2582-0192

Received: 20.07.2021

Accepted: 22.08.2021

Published: 01.09.2021

Citation:

Dhanesh, NJ. "Formation and Efficient Estimation of Stochastic Frontier Production Function." Shanlax International Journal of Economics, vol. 9 , no. 4,2021 , pp. 7-18.

DOI:

https://doi.org/10.34293/ economics.v9i4.4084

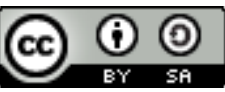

This work is licensed under a Creative Commons Attribution-ShareAlike 4.0 International License

\section{N. J. Dhanesh}

\begin{abstract}
Technological change and efficiency improvement are important sources of productivity growth in any economy. The concept of technical efficiency (TE) is based on input and output relationships. Technical inefficiency arises when actual or observed output from a given input mix is less than a possible mix. The analysis of technical efficiency involves the assessment of the degree to which the production technologies are utilized.

The present investigation on "Formation and efficient estimation of stochastic frontier production functions" was carried out in the Department of Agricultural Statistics, College of Horticulture, Vellanikkara, during 2010 -13. To assess the present economics of pepper cultivation, to formulate a new stochastic frontier production function and to compare different stochastic frontier production functions. The secondary data on the area of holdings, number of vines, yield, expenses for machinery, labour, manure, and other expenses for the cultivation of the major spice pepper collected from the Department of Plantation Crops and Spices, College of Horticulture, Vellanikkara were used for the analysis.

For the stochastic frontier production model to be realistic, an exact measurement of the cost of the inputs and the realized output is extremely necessary. Very few farmers keep records of the expenditure incurred on the various inputs and rarely the output realized.

Vegetable crops have a short duration. So the farmer will be in a position to give realistic figures regarding the various inputs as also the outputs. As regards plantation crops, there will be a lag right from the establishment of the crop to the steady bearing stage. Therefore, it will be very difficult to trace back the exact cost, as no records would be available about the costs incurred. Therefore, a rapid estimation survey is the only feasibility wherein simultaneous estimation of the costs involved from the nursery through the various stages of growth can be observed.

Since a farmer who is already having a steady-bearing crop would have incurred lesser costs through the previous stages of growth of the crop, it is most feasible to use the concept of present worth to arrive at the exact costs of previous stages of the crop. The stochastic frontier analysis was done using the present value $(P V)$ and the present cost.
\end{abstract}

Keywords: Agricultural statistics, Technology, Labour, Machinery, Production.

\section{Introduction}

Due to the lack of reliable data, very little is known about actual technical change and productivity growth in the farming communities. Productivity is an important indicator that represents the growth of each economic agent. Economists and policymakers have studied productivity for a long time. This is because, in the long run, only productivity growth is considered as an engine for economic growth. Technical efficiency is just one component of overall economic efficiency. However, to be economically efficient, a firm must first be technically efficient. Profit maximization requires a firm to produce the maximum output given the level of inputs employed (i.e., be technically efficient), use the right mix of inputs in the light of the relative price of each input (i.e., be input allocative efficient) and produce the right mix of outputs given the set of prices (i.e. be output allocative efficient) (Kumbhaker and Lovell, 2000). Technological change and efficiency improvement are important sources of productivity growth in any economy. 
The concept of technical efficiency is based on input and output relationships. Technical inefficiency arises when actual or observed output from a given input mix is less than the maximum possible. Allocative inefficiency arises when the input mix is inconsistent with cost minimization criteria (Coelli, 1996; Wang and Schmidt 2002). In saw mills, allocative inefficiency occurs when millers do not equalize marginal returns with true factor prices. The relative productive efficiency of firms within an industry is continually shocked by economic events and the process of adopting technical innovations. The diffusion of new and more efficient methods is, often, a slow, drawn-out affair. The analysis of technical efficiency involves the assessment of the degree to which production technologies are being utilized.

As the plantation crops sector is concerned, the measurement of technical efficiency is very much necessary towards the improvement of production. Availability of reliable data is a major problem towards assessing the exact technical efficiency. A plantation crop has to encompass various stages of growth before being profitable to the planter. The cost involved at various stages of growth is also very important. Vary rarely records are being kept of the exact costs involved at various stages of crop growth. Estimation of exact costs involved is a major problem. A rationalized approach is very much necessary for the estimation of exact costs. Usually, stochastic frontier production functions are fitted to crops, which are of short duration. Very rarely have works been conducted in plantation crops. With this concept in mind, a study was done to assess the present economics of pepper cultivation with the under-mentioned objectives.

- To formulate new stochastic frontier production functions.

- To compare the different methods of estimation of the frontier functions

\section{Materials and Methods}

Data collected as part of the research project "Survey on Assessment of Productivity and Production Constraints of Major Spices of Kerala", conducted by the Department of Plantation Crops and Spices, College of Horticulture, Vellanikkara was used for the study. The data include the area of holdings, number of vines, yield, expenses for machinery, labour, manure and other expenses for the cultivation of the major spice pepper.

\section{Area of Study}

The data about pepper cultivation was collected from Mananthavady. Kalpetta and Bathery blocks of Wayanad district.

\section{Estimation Methods \\ Maximum Likelihood Method}

The principle of maximum likelihood is relatively straightforward. A sample $X=(x 1, x 2 \ldots x n)$ of random variables is chosen according to a family of probabilities $\mathrm{P} \theta$. In addition, $\mathrm{f}(\mathrm{x} / \theta), \mathrm{x}=(\mathrm{x} 1, \mathrm{x} 2 \ldots$ $\mathrm{xn})$ will be used to denote the density function for the data when $\theta$ is the true state of nature.

This yields a choice of the estimator as the value for the parameter that makes the observed data most probable.

The likelihood function is the density function regarded as a function of $\theta$.

$\mathrm{L}(\theta / \mathrm{x})=\mathrm{f}(\mathrm{x} / \theta) ; \theta € \Theta \ldots(1)$

The maximum likelihood estimator (MLE), $(\mathrm{x})=$ $\max \mathrm{L}(\theta / \mathrm{x}) \ldots(2)$

The estimator has an important property. If $(\mathrm{x})$ is a maximum likelihood estimate for $\theta$, then $\mathrm{g}((\mathrm{x}))$ is a maximum likelihood estimate for $\mathrm{g}(\theta)$. For example, if $\theta$ is a parameter for the variance and is the maximum likelihood estimator, then is the maximum likelihood estimator for the standard deviation. This flexibility in estimation criterion seen here is not available in the case of unbiased estimators (Gujarati, 2003).

\section{Quasi Newton Method}

Quasi Newton method is a numerical iterative method for estimation of parameters of any mathematical model and this does not involve rigid assumptions on the error term. Quasi-Newton algorithms are arguably the most popular nonlinear numerical optimization methods, used widely in numerical applications.

\section{Present Value}

When data is collected through a rapid estimation survey, only the present cost (PC) of production at 
each stage of growth of the crop will be available. For a pepper holding which is in the steady bearing stage or any advanced stages, the exact costs involved at the previous stage of growth will be comparatively lesser. So a methodology has to be evolved to assess the various stages of growth of a holding which is already in an advanced stage of growth. So for the estimation of the exact cost, the concept of present value (PV) is adopted (clutter, 1983).

The present value of any cost involved is

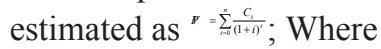

$\mathrm{C}_{\mathrm{t}}$ : - present cost in the period $\mathrm{t}, \mathrm{i}$ :- discount rate n:- number of years involved,

The overhead costs involved for the establishment of a farm up to its bearing stage as the also full yielding stage was estimated using the above formula using a discount rate of $10 \%$.

Total cost $=\frac{A G_{4}}{(1+0.1)^{+}}+\frac{A G_{5}}{(1+0.1)^{3}}+\frac{A G_{2}}{(1+0.1)^{4}}+\frac{A G_{1}}{(1+0.1)^{\prime}}$ Here AG4, AG3, AG2, and AG1 are the present

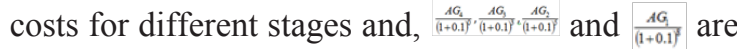
the present values for different stages

The costs involved at the full bearing stage are taken. As such, all the costs involved are estimated on a per vine basis. For all the farms in all the age group in a block, the respective overhead costs are worked out on a per vine basis. All the overhead costs of a farm are estimated based on the number of vines.

\section{Regression Equation}

It is a statistical procedure used to find relationships among a set of variables. In regression analysis, there is a dependent variable and one or more independent variables related to it. Regression is the attempt to explain the variation in a dependent variable using the variation in independent variables. Regression is thus an explanation of causation (Gujarati, 2003).

If the independent variable(s) sufficiently explains the variation in the dependent variable, the model can be used for prediction. The output of a regression is a function that predicts the dependent variable based upon the values of the independent variables. The regression equation is

$\mathbf{Y}=\boldsymbol{\beta}_{0}+\boldsymbol{\beta}_{1} \mathbf{X}_{1}+\boldsymbol{\beta}_{2} \mathbf{X}_{2}+\ldots+\boldsymbol{\beta}_{n} \mathbf{X}_{n}+\varepsilon$ Where

$\mathbf{Y}$ is the dependent variable, $\boldsymbol{\beta}_{\mathbf{0}}$ is the intercept term

$\boldsymbol{\beta}_{\mathrm{i}}$ is the regression coefficient for the ith independent variable, $i=1,2, \ldots, n \& \varepsilon$ is the error term.

\section{Production Frontier}

In this model, technical efficiency is defined as the firm's ability to produce maximum output given a set of inputs and technology. Stated differently, technical inefficiency reflects the failure of attaining the highest possible level of output for given input and technology. In contrast, Allocative (or price) Efficiency measures the firm's success in choosing the optimal input proportions, i.e., the ratio of marginal products for each pair of inputs is equal to the ratio of their market prices.

In Farrell's framework, economic efficiency measures overall performance and is equal to TE times AE. A large number of frontier models have been developed. They are based on Farrell's work and can be classified into two basic types; parametric and non-parametric. Parametric frontiers rely on a specific functional form, while non-parametric frontiers do not. Due to the data limitations, the parametric approach is followed. Another important distinction is between deterministic and stochastic frontier. The deterministic model assumes that any deviation from the frontier is due to inefficiency. The deterministic parametric approach was initiated by Aigner and Chu (1968), who estimated a CobbDouglas production frontier through linear and quadratic programming techniques.

In contrast, the stochastic approach allows for statistical noise. This is the option that we pursue, given the prevailing ignorance about actual agricultural technical processes. In the stochastic production frontier, technical efficiency is measured with a one-sided disturbance term. When explicit assumptions for the distribution of the disturbance term are introduced, the frontier function can be estimated using the maximum likelihood method. If no assumptions are made concerning the distribution of the error term, the frontier can also be estimated by the COLS, which consists of shifting the intercept term of the frontier function upwards until no positive error term remains. 


\section{Stochastic Frontier Production Functions}

The modeling, estimation and application of stochastic frontier production function to economic analysis assumed prominence in econometrics and applied economic analysis following Farrell's (1957) findings where he introduced a methodology to measure the technical, allocative and economic efficiency of a firm. According to Farrell, TE is associated with the ability of a firm to produce on the isoquant frontier. At the same time, Bravo et. al. refers to $\mathrm{AE}$ as the ability of a firm to produce at a given level of output using the cost-minimizing input ratios, thus defining EE as the capacity of a firm to produce a predetermined quantity output at a minimum cost for a given level of technology (Bravo et. al., 1997).

However, over the years, Farrell's methodology had been applied widely while undergoing many refinements and improvements. One of such improvement is the development of a stochastic frontier model, which enables one to measure firm-level technical and economic efficiency using maximum likelihood estimate COLS. Aigner et. al. (1977) and Meeusen and Van den Broeck (1977) were the first to propose stochastic frontier production function and since then, many modifications have been made to stochastic frontier analysis. Aigner et al. (1977) applied the stochastic frontier production function to analyze the U.S agricultural data. Battese and Corra (1977) applied the technique to the pastoral zone of eastern Australia. In Meeusen and Van den Broeck (1977) application, the technique was applied to analyze ten French manufacturing industries. More recently, empirical analyses have been reported by Battese et al. (1993) and Ojo (2004).

\section{Model Specification}

The stochastic frontier production function of Cobb-Douglas functional form is employed to estimate the firm-level technical and allocative efficiencies of the farmers in the study areas. The Cobb-Douglas Functional form was used because the functional form has been widely used in farm efficiency for the developing and developed countries; the functional form meets the requirement of being self-dual, allowing an examination of economic efficiency and lastly, Kopp and Smith
(1980) suggested that functional form has limited effects on empirical efficiency measurement.

The Cobb-Douglas production functional form, which specifies the production technology of the farmers, is expressed as follows:

$$
\mathrm{Yi}=\mathrm{f}(\mathrm{Xi} ; \beta) \exp (\mathrm{Vi}-\mathrm{Ui}) \ldots(1)
$$

Where Yi represents the value of output, measured in number (Number); $\mathrm{Xi}$ represents the quantity of input used in the production. The Vi's are assumed to be independently and identically distributed random errors, having normal $\mathrm{N}(0, \sigma \mathrm{v} 2)$ distribution and independent of the Ui's. The Ui's are technical inefficiency effects, assumed to be non-negative truncation of the half-normal distribution $\mathrm{N}(\mu, \sigma \mathrm{u} 2)$.

The technical efficiency of individual farmers is defined in terms of the ratio of observed output to the corresponding frontiers output, conditional on the level of input used by the farmers. Hence the technical efficiency of the farmer is expressed as:

$$
\begin{aligned}
\mathrm{TEi} & =\mathrm{Yi} / \mathrm{Yi}^{*} \\
& =\mathrm{f}(\mathrm{Xi} ; \beta) \exp (\mathrm{Vi}-\mathrm{Ui}) / \mathrm{f}(\mathrm{Xi} ; \beta) \exp \mathrm{Vi} \\
& =\exp (-\mathrm{Ui}) \ldots(2)
\end{aligned}
$$

Where: $\mathrm{Yi}$ is the observed output and $\mathrm{Yi}^{*}$ is the frontiers output. The TE ranges between 0 and 1 .

The corresponding cost frontier of Cobb - Douglas functional form, which is the basis of estimating the allocative efficiencies of the farmers, is specified as follows:

$$
\mathrm{Ci}=\mathrm{g}(\mathrm{Pi} ; \alpha) \exp (\mathrm{Vi}+\mathrm{Ui}) ;=1,2 \ldots . \mathrm{n} \ldots \text { (3) }
$$

Where $\mathrm{Ci}$ represents the total input cost of the ith farm; $g$ is a suitable function such as the Cobb-Douglas function; Pi represents input prices employed by the ith farm in food crop production and measured in naira; $\alpha$ is the parameter to be estimated, Vi's and Ui's are random errors and assumed to be independent and identically distributed truncations (at zero) of the $\mathrm{N}(\mu, \sigma 2)$ distribution. Ui provides information on the level of allocative efficiency of the ith farm. The allocative efficiency of individual farmers is defined in terms of the ratio of the predicted minimum cost $\left(\mathrm{Ci}^{*}\right)$ to observed cost $(\mathrm{Ci})$. That is: $\mathrm{AEi}=\mathrm{Ci} / \mathrm{Ci}=\exp (\mathrm{Ui}) \ldots$ (4)

Hence, allocative efficiency ranges between zero and one. 


\section{Method of Data Analysis}

Descriptive statistics viz; mean and standard deviations are used to assess socio-economic characteristics, stochastic frontier production and cost functions are used to analyse the technical and allocative efficiency respectively of farms. While the farmer's economic efficiencies are estimated as the product of $\mathrm{TE}$ and $\mathrm{AE}$, the production technology of the farmers is assumed to be specified by the Cobb-Douglas frontier production function, which is defined by;

In $Y i=\operatorname{In} \beta 0+\beta 1 \operatorname{In} X 1 i+\beta 2 \operatorname{In} X 2 i+\beta 3 \operatorname{In} X 3 i$ $+\beta 4 \operatorname{In} X 4 i+\beta 5 \operatorname{In} X 5 i+\beta 6 \operatorname{In} X 6 i+(V i-U i) \ldots(5)$

$$
\begin{aligned}
& \text { Where; } \mathrm{Y}=\text { total output }(\mathrm{kg}) \\
& \mathrm{X} 1=\text { cost } \text { of machinery (Rs) } \\
& \mathrm{X} 2 \text { = area of holdings (ha) } \\
& \mathrm{X} 3=\text { no. of vines }(\mathrm{N}) \\
& \mathrm{X} 4=\text { cost of labour (Rs) } \\
& \mathrm{X} 5=\text { cost of manure (Rs) } \\
& \mathrm{X} 6=\text { other expenses (Rs) }
\end{aligned}
$$

The variances of the random errors, $\sigma \mathrm{v} 2$ and that of the technical and allocative inefficiency effects $\sigma \mathrm{u} 2$ and overall variance of the model $\sigma 2$ are related thus: $\sigma 2=\sigma \mathrm{v} 2+\sigma \mathrm{u} 2$ and the ratio $\gamma=$ $\sigma u 2 / \sigma 2$, measures the total variation of output from the frontier which can be attributed to technical or allocative inefficiency (Battese and Corra, 1977). The estimates for all the parameters of the stochastic frontier production function and the inefficiency model are simultaneously obtained using the program FRONTIER version 4.1c (Coelli, 1996).

\section{Technical Efficiency: The Concept and Basic Model}

While the concept of technical efficiency is as old as neoclassical economics, interest in its measurement is not. This is probably explained by the fact that neoclassical production theory presupposes full technical efficiency. Then, the question arises as to why one should measure technical efficiency. There are two principal arguments for its measurement. The first and most compelling reason lies in recognizing that a gap exists between the theoretical assumption of full technical efficiency and empirical reality. Leibenstein (1966) drew attention to this in the sixties. Second, on a priori reasoning, there is a high probability that, where technical inefficiency exists, it will influence allocative efficiency and that there will be a cumulative negative effect on economic efficiency (Bauer, 1990). Following this logic, technical efficiency becomes central to achieving high levels of economic performance at the firm level, as does its measurement.

The basic concept underpinning the measurement of technical efficiency starts with the description of production technology. Production technologies can be represented using isoquant, production functions, and cost functions or profit functions. These four models provide four different tools for measuring technical efficiency. Although analyses based on these models appear to be distinct, they constitute the same basic approach and ideally, their results should converge.

It has been acknowledged in the literature that, in reality, a gap normally exists between a firm's actual and potential levels of technical performance. This carries conceptual implications for the understanding of the measurement of efficiencies, which can be understood with the help of figure 1.1.

In neoclassical theory, all firms operate at potential technical efficiency, at points along the frontier FF'. Any inefficiency will be solely allocative. Thus, if a firm is operating on its frontier FF', its point of economic efficiency may be at B' the point of tangency with its price line. If it operates at B, with input I1 and output Q1 there will be maximum profit $\pi 1$ and no allocative or economic inefficiency. It should be noted that provided firms are operating on their technical frontiers, allocative (in) efficiency will be the same as economic (in) efficiency (they are used synonymously in the literature) because of the theoretical assumption of potential technical efficiency. Thus if a firm is operating at point A on its frontier, using I2 input and producing Q2 output its profits may be $\pi 2$, and its allocative/economic inefficiency will be measured as $\pi 2 / \pi 1$. 


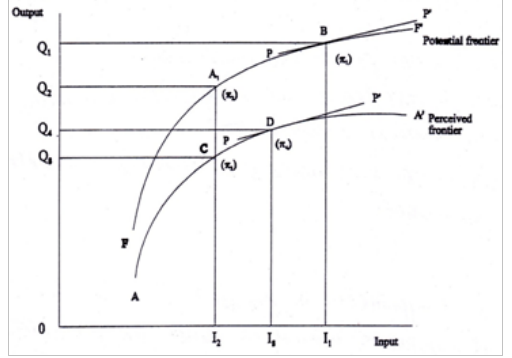

Figure 1.1 The concepts of firm-specific technical efficiency, allocative efficiency and economic efficiency

Note: Figures in parentheses refer to net profits associated with concerning inputs and technology.

In practice, with new technology, firms operate at less than potential technical efficiency owing to incomplete knowledge of best technical practices or to other organizational factors that prevent them from operating on their technical frontier. Thus, a firm will operate on an actual or perceived production function below the potential frontier, e.g. on AA' in Figure 1. At I2 input, it operates at point $\mathrm{C}$, produces $\mathrm{Q} 3$ output and earns $\pi 3$ profit. On this actual production function, point $\mathrm{C}$ is allocatively inefficient. To maximize its profit $(\pi 4)$ it would have to operate at point $\mathrm{D}$, use I3 input and produce Q4 output. At D, however, it would not achieve potential economic efficiency, for by definition, potential economic efficiency can only be achieved with potential technical efficiency.

To be consistent with neoclassical production theory, efficiency should only be measured about the frontier production function FF'. Thus if a firm is operating at $\mathrm{C}$ on its actual or perceived production function, its economic inefficiency would be measured in profit terms by the ratio $\pi 2 / \pi 1$, or in output terms by the ratio Q2/Q1.

Now, it can easily be seen in Figure I that this economic inefficiency comprises two components, technical and allocative inefficiencies. In profit terms, the total loss in economic inefficiency in operating at point $\mathrm{C}$ is $\pi 1-\pi 3$. Of this, the loss from technical inefficiency is $\pi 3-\pi 2$, and the loss due to allocative inefficiency is $\pi 1-\pi 2$. In output terms, the losses are Q2 - Q3 and Q1 - Q2, respectively.

\section{Results and Discussion \\ Comparison of the Costs of Various Inputs for the Different age Groups}

The costs incurred under the various overheads for the different age groups in each block were summarized per vine basis and compared using a one-way analysis of variance. The results are discussed as follows

\section{Mananthavady Block}

The expenditures incurred under various heads were found to be maximum for age group four and were significantly higher. It was observed that an amount of Rs. 7.61 for machinery, Rs. 168for labor, Rs. 23 for manure and Rs. 15 for other expenses were incurred.

\section{Kalpetta Block}

The expenditures incurred under various heads were found to be maximum for age group four and were significantly higher. It was observed that an amount of Rs. 1.65 for machinery, Rs. 51 for labour, Rs. 15 for manure and Rs. 1 for other expenses were incurred.

\section{Bathery Block}

The expenditures incurred under various heads were found to be maximum for age group four and were significantly higher. It was observed that an amount of Rs. 0.86 for machinery, Rs. 42 for labour, Rs. 10 for manure and Rs. 2 for other expenses were incurred.

From the summary statistics, it was found that Irrespective of the blocks, the expenditure on labour charges was the highest followed by manure charges. It was increasing according to the increase in age of the plants.

\section{Formation and Estimation of Stochastic Frontier}

From the summary statistics listed above, it is evident that a wide range of variation existed in the costs towards machinery, labour, manure and other expenses for all the pepper plantations in different age groups in all the three blocks surveyed. Being a rapid estimation survey all the costs were evaluated based on the prevailing conditions. A pepper plantation, which is eight years old and above, might 
have incurred a lesser cost at the time of planting. Similar would be the case with the other two age groups namely, two to three years old and four to seven years old. Similarly, lesser costs only would have been incurred for the subsequent establishment of a plantation at the different stages of growth. Therefore, a rationale is necessary for assessing the present allocation of the costs towards establishing maximum production efficiency. The stochastic frontier approach is well suited for this purpose with the rationalized cost. To assess the differences in the estimate of production efficiency computed based on the cost at the present situation and to compare the same with the production efficiency computed with PV, Stochastic Frontier Analysis been done,

- Separately for each age group in the different blocks using present costs.

- For each age group by pooling over the blocks using present value

- For each block with age groups, three and age group four combined using present value.

- For all the three blocks, compounding all the costs starting from the nursery stage (First age group) up to the steadily bearing stage (Fourth age group) using present value.

\section{SFA for each Block with Age Groups Three and Age Group Four Combined using PV Mananthavady}

The mean technical efficiency was 0.95. All the plantations in this block had an above-average performance.

\section{Kalpetta}

The mean technical efficiency was 0.81 . The highest technical efficiency of 0.96 was observed for plantation K-AG.4-01 and K-AG.3-07. The lowest technical efficiency was for the plantation K-AG.301(0.34).

\section{Bathery}

The mean technical efficiency was 0.92 . The lowest technical efficiency was 0.5496 and was seen in plantation B-AG.4-06. The highest technical efficiency was observed in the plantations B-AG.301, B-AG.3-02 and B-AG.4-05 (1.00).
SFA for all the Three Blocks Compounding all the Costs Starting from the Nursery Stage (First Age Group) up to the Steadily Bearing Stage (Fourth Age Group) using Present Valve

\section{Mananthavady (PV)}

The mean technical efficiency was 0.93. The lowest technical efficiency was 0.87 for the plantations M-AG.4-02 and M-AG.4-05. The highest technical efficiency was for the plantation M-AG.404 (0.97).

\section{Kalpetta}

The mean technical efficiency was 0.91. The lowest technical efficiency 0.78 and was seen in the plantation K-AG.4-07. The highest technical efficiency was seen in the plantation K-AG.4-06 and K-AG.4-10 (1.00).

\section{Bathery}

The mean technical efficiency was 0.94. The lowest technical efficiency 0.87 was seen in the plantation B-AG.4-05. The highest technical efficiency was seen in the plantation B-AG.4-03 (0.98).

\section{Farm Specific Technical Efficiency in Different Blocks}

The technical efficiency of all the plantations considered for the study has a value equal to or greater than 80 percent. In Mananthavady, 80 percentage of the farms were having a technical efficiency greater than or equal to 0.9. In Bathery also 90 percent of the farms showed technical efficiency greater than 0.9 , Whereas in Kalpetta only 50 percent of the farms were technically efficient in the range 0.9 to 1 . The attainment of technical efficiency of 80 percent indicates that the efficiency of the farmers could be increased by about 28 per cent to attain the maximum possible output. The results also suggest that farmers could increase output through more intensive labour, vine and fertilizer inputs given the prevailing state of technology. 


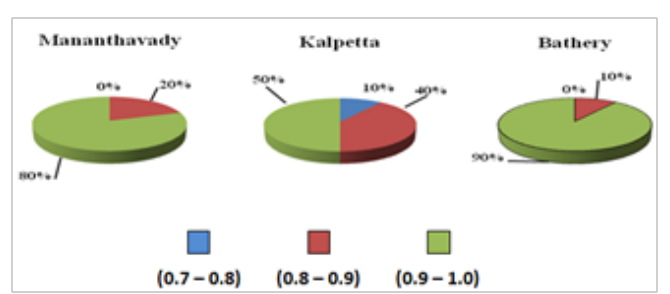

Figure 2.10 Farm specific technical efficiency in different blocks

\section{Comparison of Technical Efficiency Estimated} using Present Costs and Present Value

Improved technical efficiencies were obtained for the plantations in the fourth age group of Mananthavady and Kalpetta. As regards Bathery not many differences were noticed. Estimation of TE using PV is advantageous when technical efficiencies are computed by combining the third age group, which is in its early stage of bearing, and the fourth age group, which is in its full bearing stage. It is quite advantageous to have a realistic estimate of the costs right from establishing the nursery. It will be extremely worthwhile to analyze the factors that influence the TE. For this purpose, the regression of TE on the factors like the area of holdings, number of vines, expenses for machinery, labour, manure and other expenses was obtained.

\section{Factors Affecting Technical Efficiency}

Factors affecting the technical efficiency were identified by fitting regression of TE on the variables viz; area of holdings, number of vines, the expense for machinery, labour, manure and other expenses. The fit was good for the data from Mananthavady and Kalpetta blocks.

The regression equation for Mananthavady could explain 97 percent variation in technical efficiency. The inputs like area of holdings, number of vines, machinery, labor, manure and other expenses were significantly contributing to TE. The area of holdings, number of vines, and other expenses negatively influenced TE, whereas expenses for labour and manure positively influenced TE.

The regression equation for Kalpetta could explain 97 percent variation in technical efficiency. The inputs like area of holdings, number of vines, machinery, labour, manure and other expenses were significantly contributing to TE. The expenses for machinery, manure and other expenses positively influenced TE, whereas the holdings area negatively influenced TE.

In general, the area of holdings increased, the technical efficiency seemed to decrease. This is in agreement with the findings of Ali et. al. (1996), who observed that the size of holding and fragmentation of land of farmers contributed positively to inefficiency. The non-optimum use was explained by holding size, education, credit, and subsistence needs. Small farms seemed to be more efficient than large farms in the region.

\begin{tabular}{|l|c|c|c|c|c|c|c|c|c|}
\hline & \multicolumn{3}{|c|}{ Mananthavady } & \multicolumn{3}{c|}{ Kaltpetta } & \multicolumn{3}{c|}{ Bathery } \\
\hline & B & \multicolumn{1}{|c|}{ T } & Sig. & B & t & Sig. & B & t & Sig. \\
\hline (Constant) & 0.851 & 57.4446 & 0 & 1.3198 & 18.86 & 0.0003 & 0.8242 & 12.0696 & 0.0012 \\
\hline Area of holdings (x1) & -0.0015 & -3.2468 & 0.0476 & -0.2276 & -5.3631 & 0.0127 & 0.0118 & 0.4904 & 0.6575 \\
\hline No. of Vines (x2) & -0.0013 & -2.9934 & 0.058 & -0.0019 & -2.4369 & 0.0928 & -0.0002 & -0.3708 & 0.7354 \\
\hline Machinery (x3) & 0.0001 & 2.2129 & 0.1138 & 0.0002 & 6.3007 & 0.0081 & 0.0001 & 0.9238 & 0.4237 \\
\hline Labour (x4) & 0.0001 & 4.3635 & 0.0223 & 0.0001 & -5.6945 & 0.0107 & 0.0001 & 0.9323 & 0.42 \\
\hline Manure (x5) & 0.0001 & 2.183 & 0.117 & 0.0002 & 6.8456 & 0.0064 & 0.0001 & -0.8491 & 0.4582 \\
\hline Other Exp. (x6) & -0.0001 & -5.3272 & 0.0129 & 0.0004 & 4.2322 & 0.0241 & 0.0001 & -0.2857 & 0.7937 \\
\hline R Square & \multicolumn{4}{|c|}{0.9733} & \multicolumn{3}{|c|}{0.9671} \\
\hline
\end{tabular}

With proper labour management, technical efficiency can be significantly increased. This is in agreement with the findings of Ahmed et. al. (2005) who pointed that credit, capital, hired labor, fertilizer and irrigation had significant positive effects on sorghum production levels, while the sorghum area showed a negative and significant effect. Size of holding, education level, tenants' experience, 
household size, contact with extension agents and farm location were significant in explaining tenants' technical inefficiency. Alemu et. al. (2009) observed that maximum likelihood estimates indicated positive and significant elasticities for inputs such as land, labour and fertilizer. Besides, education, proximity to markets, and access to credit were found to reduce inefficiency levels significantly. The predicted coefficient of household size was negative and is significant at 5 percent.

\begin{tabular}{|c|c|c|}
\hline Sl. No. & Regression equation & $R^{2}(\%)$ \\
\hline 1 & $\begin{array}{l}T . E_{(M)}=0.8510_{(0.0148)}-0.0015_{(0.0005)}^{\prime} x_{1}-0.0013_{(0.0004)}^{*} x_{2} \\
+0.0001_{(0.0001)}, x_{3}+0.0001_{(0.0001)}^{*} x_{4}+0.0001_{(0.0001)}^{*} x_{5}-0.0001_{(0.0001)}^{*} x_{5}\end{array}$ & 97 \\
\hline 2 & $\begin{array}{l}T . E_{(K)}=1.3198_{(0.0700)}-0.2276_{(0.0424)^{*}}^{*} x_{1}-0.001{ }_{(0.0008)} x_{2} \\
+0.0002_{(0.0001)}^{*} x_{3}+0.0001_{(0.0001)}^{*} x_{4}+0.0002_{(0.0001)} x_{1}+0.0004_{(0-0001)}^{*} x_{6}\end{array}$ & 97 \\
\hline 3 & $\begin{array}{l}T . E_{(B)}=0.8242_{(0.0683)}+0.0118_{(0.0240)} x_{1}-0.0002_{(0.0005)} x_{2} \\
+0.0001_{(0.00001)} x_{3}+0.0001_{0.0001} x_{4}+0.001_{(00000)} x_{5}+0.0004_{(0.0001)} x_{6}\end{array}$ & 76 \\
\hline
\end{tabular}

Managing all the requirements of the crop over a large holding area might be difficult, especially for want of a sufficient labour force. This is further reinforced by the more labour intensive, the more profitable the crop is. Retention of senile and productive vines might be another factor negatively influencing TE. Agbonlahor, M. U. (2010) recommended that technical and management training/workshops should be organized by relevant government agencies to regularly update operators' knowledge. Import policies should be targeted to encourage the acquisition and use of modern sawmilling machines and equipment. Also, the public power supply to the sawmill clusters should be improved to reduce the high processing cost associated with diesel-powered electricity generation sets. We can also recommend that kind of extension program in pepper cultivars. Wakili (2012) observed that the inefficiency variable was specified as those relating to farmer's socioeconomic characteristics. They include the farmer's level of educational attainment, membership of an association, contact with extension agents, household size and gender.

Miniraj and Nybe (2011) reported that predominance of poor genetic stock, the incidence of disease and pests and non-adaption of scientific cultivation practices are the major factors affecting pepper cultivation. In wayanad 77 percent of farmers applied organic manures alone while 22 percent applied organics along with inorganic. There were 30 farms that were certified organic, most of which were situated in Sulthan Bathery panchayath. It may be noted that there are several NGO's in Wayanad who promote organic farming in pepper under various certification procedures.

Among diseases, foot rot incidence was high $(91 \%)$ in all the panchayats. Slow wilt and another disea,se including little leaf, damaged six percent of vines whereas three percent of vines were reported to be free from any disease. Concerning infestation of pests on pepper vine, 99 percent of farms were free of any pests. The incidence of thrips and other minor pests was insignificant. It may be noted that in wayanad, more than the vine, it was the standard, which was affected by pests. It is to be emphasized that erythrina trees in Wayanad have been drastically infested by the wasp and have almost totally wiped out from certain pockets.

\section{Conclusion}

Usually, stochastic frontier models are fitted to data of crops, which are having a duration of less than one year. This is because; the cost of cultivation is readily available. If there were records of the exact cost of cultivation, as in the case with vegetable crops, there might be no problem fitting stochastic frontier models to any phenomena involving output and a vector of inputs. This is usually possible in industries such as many a literature are available on stochastic frontier models related to industries.

As regards the scenario of agriculture where output is of prime importance for a set of inputs, the stochastic frontier model will be the description of a notion that has to set right the present system and bring an output, which is much attractive. The usually heard word that cultivation of any crop is unattractive has to be set apart.

Very few farmers record the expenditure incurred on the various inputs, and very rarely, the output is realized. A surveyor usually finds it difficult to elucidate the exact cost of inputs and the realistic output as he is at the mercy of the respondent for information.

Stochastic frontier approaches have never been tried in the plantation crops sector, where the plantations take a stipulated time to give a fruitful 
output right from the stage of establishment. As total cost from the establishment stage itself is necessary to have a stochastic frontier model fitted to plantation crops, realistic cost estimation for the different stages of establishment is necessary.

A farmer's hypothetical figure for the cost involved at the various stages of establishment of the crop is of no use to arrive at a summary figure. For this purpose, a rapid estimation survey was conducted in Mananthavady, Kalpetta and Bathery blocks. Being a rapid estimation survey, all the costs were evaluated based on the prevailing conditions. A pepper plantation, which is eight years old and above, might have incurred a lesser cost at the time of planting. Similar would be the case with the other two age groups, namely, two to three years old and four to seven years old.

Similarly, lesser costs only would have been incurred for the subsequent establishment of a plantation at the different stages of growth. Therefore, a rationale is necessary for assessing the present allocation of the costs towards establishing maximum production efficiency. The stochastic frontier approach is well suited for this purpose with the rationalized cost. To assess the differences in the estimate of production efficiency computed based on the cost at the present situation and to compare the same with the production efficiency computed with Present Value (PV), Stochastic Frontier Analysis (SFA) has been done separately using both the costs.

The mean area of holdings under the first age group was 7.61 acres, with a mean number of 325 vines in the Mananthavady block. The corresponding mean figures regarding machinery, labour, manure and other expenses were Rs. 399, Rs. 15383, Rs. 1730 and Rs. 3340 respectively. Regarding the second age group, the mean figures were 9.22 acre, 282 nos., Rs. 812, Rs. 15583, Rs. 4695 and Rs. 1215 for the holdings area, number of vines, machinery, labour, manure and other expenses, respectively. Concerning the third age group, the mean figures were 5.17 acre, 362 nos., Rs. 911, Rs. 41045, Rs. 6070, Rs. 5610 and $1035 \mathrm{~kg}$. for the holdings area, number of vines, machinery, labour, manure, other expenses and yield, respectively. In the fourth age group, the mean figures were 8.64 acre, 90 nos., Rs. 592, Rs. 14068, Rs. 1905 , Rs. 1250 and $374.5 \mathrm{~kg}$. for the holdings area, number of vines, machinery, labour, manure, other expenses and yield, respectively.

In Kalpetta block, the mean area of holdings under the first age group was 1.69 acres with a mean number of 401 vines. The corresponding mean figures as regards machinery, labour, manure and other expenses were Rs. 789, Rs. 6260, Rs. 1302 and Rs. 2680 respectively. Regarding the second age group, the mean figures were 0.94 acres, 295 nos., Rs. 168, Rs. 8890, Rs. 1990 and Rs. 265 for the holdings area, number of vines, machinery, labour, manure and other expenses, respectively. In the third age group, the mean figures were 1.34 acre, 240 nos., Rs. 446, Rs. 11760 , Rs. 3135, Rs. 365 and $193 \mathrm{~kg}$. for the holdings area, number of vines, machinery, labour, manure, other expenses and yield, respectively. Concerning the fourth age group, the mean figures were 1.43 acre, 300 nos., Rs. 576, Rs. 15115 , Rs. 4370 , Rs. 290 and $260 \mathrm{~kg}$. for the holdings area, number of vines, machinery, labour, manure, other expenses and yield, respectively.

In the Bathery block, data for the second age group was not available. The mean area of holdings under the first age group was 2.50 acres with a mean number of 680 vines. The corresponding mean figures as regards machinery, labour, manure and other expenses were Rs. 1211, Rs. 13283, Rs. 2070 and Rs. 5710 respectively. Regarding the third age group, the mean figures were 2.40 acre, 540 nos., Rs. 661, Rs. 18950 , Rs. 5420 , Rs. 615 and 277.5 kg. for the holdings area, number of vines, machinery, labour, manure, other expenses and yield, respectively. Concerning the fourth age group, the mean figures were 2.50 acre, 435 nos., Rs. 351, Rs. 15890, Rs. 4250, Rs. 670 and $238 \mathrm{~kg}$. for the area of holdings, number of vines, machinery, labour, manure, other expenses and yield, respectively.

Irrespective of the blocks, the expenditure on labour charges was the highest followed by manure charges and it was increasing according to the increase in age of plants. A wide range of variation existed towards the area of holdings, several vines, machinery, labour, manure and other expenses for all the pepper plantations in the different age groups in the entire three blocks surveyed. The stochastic frontier analysis was done using the PV as also with the PC. The SFA was done separately for each age 
group in the different blocks using $\mathrm{PV}$, for each age group by pooling over the blocks using PV, for each block with age groups three and age group four combined using PV, and for all the three blocks compounding all the costs starting from the nursery stage (First age group) up to the steadily bearing stage(Fourth age group) using PV.

The SFA for each age group in the different blocks using present costs revealed a mean technical efficiency 0.79 for the plantations in the third age group and a mean technical efficiency of 0.92 for the plantations in the fourth age group Mananthavady block. The corresponding mean technical efficiency for the plantations in the third and fourth age groups of Kalpetta and Bathery blocks were 0.73, 0.84; $0.58,0.94$, respectively.

The stochastic frontier approach for each age group by pooling over the blocks, worked out using $\mathrm{PV}$, revealed a mean technical efficiency of 0.95 and 0.92 for the plantations in the third and fourth age group, respectively.

The SFA for each block with age groups three and four combined using PV resulted in a mean technical efficiency of 0.95 for Mananthavady, 0.78 for Kalpetta and 0.92 for Bathery blocks.

The SFA for all the three blocks compounding all the costs starting from the nursery stage (First age group) up to the steadily bearing stage(Fourth age group) using PV was worked out. The mean technical efficiency was $0.93,0.91$ and 0.94 for Mananthavady, Kalpetta and Bathery Blocks, respectively.

In all the modes of estimation of technical efficiency using SFA analysis, improved estimates of technical efficiency were obtained. To further assess the factors influencing technical efficiency, the regression of TE. on the factors like the area of holdings, no. of vines, expenses for machinery, labour, manure and other expenses was obtained.

Factors affecting the technical efficiency were identified by fitting regression of TE. on the variables viz; area of holdings, number of vines, the expense for machinery, labour, manure and other expense. Using the above variables 97 percent of the variation in T.E. could be explained. When the area of holdings increased, the technical efficiency seemed to decrease. With proper labour management, technical efficiency can be significantly increased. Managing all the requirements of the crop over a large holding area might be difficult, especially for want of sufficient labour force. This is further reinforced by the fact that more labour intensive, more profitable the crop is. Retention of senile and productive vines might be another factor negatively influencing TE.

\section{References}

Agbonlahor, M.U. "Productivity Dispersion and Resources of Technical Inefficiency in Small Holder Timber Mills in Ogun State, Nigeria." Journal of Humanities, Social Sciences and Creative Arts, vol. 5, 2010, pp. 49-60.

Ahmed, A.E., et al. "Analysis of Factors Affecting Sorghum Production in the Gezira Scheme - Sudan and Implications on the Household Food Security." Conference on International Agricultural Research for Development, 2005, pp. 11-13.

Aigner, Dennis, et al. "Formulation and Estimation of Stochastic Frontier Production Function Models." Journal of Econometrics, vol. 6, no. 1, 1977, pp. 21-37.

Aigner, D.J., and S.F. Chu. "On Estimating the Industry Production Function.” The American Economic Review, vol. 58, no. 4, 1968, pp. 826-839.

Alemu, Bamlaku A., et al. "Technical Efficiency Across Agro-Ecological Zones in Ethiopia: The Impact of Poverty and Asset Endowments." Agricultural Journal, vol. 4, no. 4, 2009, pp. 202-207.

Ali, Farman, et al. "Measurement of Economic Efficiency using the Behavioral and Stochastic Cost Frontier Approach." Journal of Policy Modeling, vol. 18, no. 3, 1996, pp. 271-287.

Battese, George, and Tim J Coelli. A Stochastic Frontier Production Function Incorporating a Model for Technical Inefficiency Effects. University of New England, 1993.

Battese, George E., and Greg S. Corra. "Estimation of a Production Frontier Model: With Application to the Pastoral Zone of Eastern Australia." Australian Journal of Agricultural Economics, vol. 21, no. 3, 1977, pp. 169-179.

Bauer, Paul W. "Recent Developments in the Econometric Estimation of Frontiers." Journal of Econometrics, vol. 46, 1990, pp. 39-56.

Bravo-Ureta, Boris E., and Antonio E. Pinheiro. 
"Technical, Economic and Allocative Efficiency in Peasant Farming: Evidence from the Dominican Republic." The Developing Economics, vol. 35, no. 1, 1997, pp. 48-67.

Coelli, Timothy James. Specification and Estimation of Stochastic Frontier Production Functions. University of New England, 1996.

Farrell, M.J. "The Measurement of Production Efficiency." Journal of the Royal Statistical Society, vol. 120, no. 3, 1957, pp. 253-290.

Gujarati, Damodar N., and Dawn C. Porter. Basic Econometrics. McGraw-Hill, 2003.

Liebenstein, Harvey. "Allocative Efficiency vs. X-Efficiency." The American Economic Review, vol. 56, no. 3, 1966, pp. 392-415.

Meeusen, Wim, and Julien van Den Broeck. "Efficiency Estimation from Cobb-Douglas Production Functions with Composed Error." International Economic Review, vol. 18, no. 2, 1977, pp. 435-444.

\section{Author Details}

N. J. Dhanesh, Email ID: dhaneshnj16@gmail.com.
Ojo, S.O. "Improving Labour Productivity and Technical Efficiency in Food Crop Production: A Panacea for Poverty Reduction in Nigeria." Food and Agriculture Environment, vol. 2, no. 2, 2004, pp. 227-231.

Wakili, Abba Mohammad. "Technical Efficiency of Sorghum Production in Hong Local Government Area of Adamawa State, Nigeria." Russian Journal of Agricultural Socio-Economic Sciences, vol. 6, no. 6, 2012, pp. 10-15.

Wang, Hung-jen, and Peter Schmidt. "One-Step and Two-Step Estimation of the Effects of Exogenous Variables on Technical Efficiency Levels." Journal of Producitivity Analysis, vol. 18, 2002, pp. 129-144. 